\title{
Electrophysiological evidence for glial-subtype glutamate transporter functional expression in rat cerebellar granule neurons
}

R.A. Mafra ${ }^{1,2}$, R.M. Leão ${ }^{1,3}$, P.S.L. Beirão ${ }^{1}$ and J.S. Cruz ${ }^{1}$

\section{Correspondence}

J.S. Cruz

Departamento de Bioquímica e Imunologia, ICB, UFMG

Caixa Postal 486

30161-970 Belo Horizonte, MG

Brasil

E-mail: jcruz@icb.ufmg.br

Research supported by CNPq. Publication supported by FAPESP. R.A. Mafra, P.S.L. Beirão and

J.S. Cruz were recipients of

research fellowships from $\mathrm{CNPq}$.

\author{
'Laboratório de Membranas Excitáveis, Departamento de Bioquímica e Imunologia, \\ Instituto de Ciências Biológicas, Universidade Federal de Minas Gerais, \\ Belo Horizonte, MG, Brasil \\ 2Departamento de Biologia Molecular, Centro de Ciências Exatas e da Natureza, \\ Universidade Federal da Paraíba, João Pessoa, PB, Brasil \\ ${ }^{3}$ Departamento de Fisiologia, Faculdade de Medicina de Ribeirão Preto, \\ Universidade de São Paulo, Ribeirão Preto, SP, Brasil
}

Received November 25, 2002 Accepted April 11, 2003 $\ldots \ldots \ldots \ldots \ldots \ldots \ldots$

\begin{abstract}
A glutamate-sensitive inward current (Iglu) is described in rat cerebellar granule neurons and related to a glutamate transport mechanism. We examined the features of Iglu using the patch-clamp technique. In steady-state conditions the Iglu measured $8.14 \pm 1.9$ pA. Iglu was identified as a voltage-dependent inward current showing a strong rectification at positive potentials. L-Glutamate activated the inward current in a dose-dependent manner, with a half-maximal effect at about $18 \mu \mathrm{M}$ and a maximum increase of $51.2 \pm 4.4 \%$. The inward current was blocked by the presence of dihydrokainate $(0.5 \mathrm{mM})$, shown by others to readily block the GLT1 isoform. We thus speculate that Iglu could be attributed to the presence of a native glutamate transporter in cerebellar granule neurons.
\end{abstract}

Key words

- Cerebellar granule neurons

- Excitatory amino-acid

transporter type 2

- Patch-clamp

- Glutamate

- Whole-cell voltage-clamp

\section{Introduction}

Neurotransmitters are stored in and released from vesicles in the narrow space of the synaptic cleft. When released they bind to their postsynaptic receptors, causing biophysical and metabolic changes, and their rapid removal is essential for fast synaptic transmission reliability. In the glutamatergic synapse, the estimated peak of glutamate in the cleft during a synaptic event is estimated to be of the order of 1-3 mM, and glutamate is removed with a time constant of 1-2 ms (1). Two mechanisms are thought to be re- sponsible for this clearance: a) constricted diffusion and $b$ ) the buffering capacity of glutamate transporters $(1,2)$. Glutamate can affect extrasynaptic receptors even in neighboring neurons, an event known as "spillover" neurotransmission $(3,4)$. Reuptake of extrasynaptic glutamate is then crucial to prevent a continuous rise in glutamate concentration, which may lead to neurotoxic effects $(5,6)$.

It has been established that glial $\mathrm{Na}^{+}-$ dependent glutamate transporters have an important role in the clearance of the synaptically released glutamate $(7,8)$. Although 
neurons also express glutamate transporters $(9,10)$, in most cases they seem to play a small role in removing the extracellular glutamate (11). The mossy fiber-cerebellar granule neuron-Golgi cell synapse is encapsulated by surrounding astrocytes in a special structure called glomerulus (12), which is supposed to enhance the "spillover" transmission, at least for GABA $(13,14$; see also $15)$. The astrocyte processes lining the dendritic trees on the glomerulus have a high density of glutamate transporters of the GLT-1 and GLAST subtypes. Inhibition of these transporters has little effect on the duration of the non-N-methyl-D-aspartate excitatory postsynaptic current (non-NMDA EPSC) component (16). Conversely, the inhibition has been shown to prolong the nonNMDA EPSC at the level of the auditory nerve synapse in the nucleus magnocellularis and of the cerebellar parallel and climbing fiber synapses, and during repetitive stimulation of the cerebellar mossy fiber synapse when $\alpha$-amino-3-hydroxy-5-methylisoxazole-4-propionic acid receptor desensitization is blocked (17-19). In addition, glutamate uptake determines the duration of the NMDA component of the EPSC at the level of the cerebellar mossy fiber synapse and cultured hippocampal synapses $(19,20)$. Since the presence of glutamate transporters has been suggested in cerebellar granule neurons by immunoblotting techniques (21), we were interested in examining if cerebellar granule neurons could be used as a model to study the native glutamate transport, since most studies make use of heterologous expression systems which may lack a physiological component.

In the present study, we report data supporting the functional expression of a glialsubtype glutamate transporter in neuronal cells. First, we demonstrate the presence of a transporter current evoked by extracellular perfusion of L-glutamate. Second, we show that this current does require extracellular $\mathrm{Na}^{+}$. Finally, we show that the current is blocked by dihydrokainate, a well-known glial-subtype glutamate transporter (EAAT2/ GLT1).

\section{Material and Methods}

\section{Drugs and reagents}

All chemicals used in this study were obtained from Sigma (St. Louis, MO, USA), Gibco-Life Technologies (Gaithersburg, MD, USA) and Tocris Neurochemicals (dihydrokainate; Langford, Bristol, UK).

\section{Cell culture}

Cells were cultured as described elsewhere (15). Briefly, newborn Wistar rats (postnatal day 5) were killed by decapitation following the Institutional Guidelines for Animal Experimentation. Cerebella were dissected and placed in Hanks' solution of the following composition: $136.9 \mathrm{mM} \mathrm{NaCl}$, $5.3 \mathrm{mM} \mathrm{KCl}, 0.44 \mathrm{mM} \mathrm{KH}_{2} \mathrm{PO}_{4}, 0.33 \mathrm{mM}$ $\mathrm{Na}_{2} \mathrm{HPO}_{4}, 4 \mathrm{mM} \mathrm{NaHCO}_{3}, 5.5 \mathrm{mM}$ glucose, adjusted to $\mathrm{pH} 7.4$ with $1 \mathrm{M} \mathrm{NaOH}$. We then added $50 \mu \mathrm{g} / \mathrm{ml}$ penicillin/streptomycin. The tissue was enzymatically digested with 2.5 $\mathrm{mg} / \mathrm{ml}$ trypsin for 4 min and mechanically dissociated in Hanks' solution containing $12 \mathrm{mM} \mathrm{MgCl}{ }_{2}$ and $1 \mathrm{U} / \mathrm{ml}$ DNase using Pasteur pipettes of different diameters. The cells were plated onto poly-D-lysine-coated glass coverslips and maintained in culture $\left(37^{\circ} \mathrm{C}, 5 \% \mathrm{CO}_{2}\right)$ in Dulbecco's modified Eagle's medium supplemented with $10 \%$ fetal bovine serum, $100 \mathrm{mg} / \mathrm{l}$ transferrin and 25 $\mathrm{mg} / \mathrm{l}$ insulin. After $48 \mathrm{~h}$ in culture, the medium was changed and $4 \mathrm{mM}$ cytosine arabinoside was added to stop glial cell proliferation.

\section{Electrophysiology}

Before recording, the culture medium was exchanged with standard Tyrode solution: $120 \mathrm{mM} \mathrm{NaCl}, 5 \mathrm{mM} \mathrm{KCl}, 2 \mathrm{mM}$ 
$\mathrm{CaCl}_{2}, 1 \mathrm{mM} \mathrm{MgCl} 2,10 \mathrm{mM}$ glucose, and 5 $\mathrm{mM}$ HEPES-NaOH, $\mathrm{pH}$ 7.4. The recording chamber was filled with Tyrode solution at room temperature $\left(23^{\circ}-28^{\circ} \mathrm{C}\right)$. Individual cerebellar granule neurons were visually identified by their distinctive size ( $\sim 5 \mu \mathrm{M}$ in diameter) and shape (a round to oval bipolar neuron). Whole-cell recordings were carried out with 5- to $10-\mathrm{M} \Omega$ resistance micropipettes (22).

The capacity current was canceled using the computer-assisted facility of the patchclamp amplifier (HEKA-EPC9, Lambrecht/ Pfalz, Germany). Membrane currents were usually filtered at $2.5 \mathrm{kHz}$ and sampled at 10 $\mathrm{kHz}$. The pipette solution contained $120 \mathrm{mM}$ $\mathrm{KCl}, 5 \mathrm{mM} \mathrm{NaCl}, 10 \mathrm{mM}$ tetraethylammonium chloride (TEACl), $5 \mathrm{mM}$ EGTA, and 5 $\mathrm{mM}$ HEPES, and was adjusted to $\mathrm{pH} 7.2$ with $\mathrm{KOH}$. The extracellular bath test solution contained $120 \mathrm{mM} \mathrm{NaCl}, 5 \mathrm{mM} \mathrm{KCl}, 10$ $\mathrm{mM}$ glucose, $2 \mathrm{mM} \mathrm{CaCl}_{2}, 20 \mathrm{mM}$ TEACl, 5 $\mathrm{mM}$ 4-aminopyridine (4-AP), $1 \mathrm{mM} \mathrm{CdCl}_{2}$, $0.1 \mu \mathrm{M}$ tetrodotoxin (TTX), $1 \mu \mathrm{M}$ ouabain, $50 \mu \mathrm{M}$ 6-cyano-7-nitroquinoxaline 2,3 dione (CNQX), D (-)-2-amino-5-phosphono-pentanoic acid (AP5), and $5 \mathrm{mM}$ HEPES, and was adjusted to $\mathrm{pH}$ 7.4. TEACl and 4-AP were used to block voltage-dependent $\mathrm{K}^{+}$ channels, TTX is a well-known $\mathrm{Na}^{+}$channel blocker, cadmium inhibits $\mathrm{Ca}^{2+}$ channels, ouabain blocks $\mathrm{Na} / \mathrm{K}$ ATPase, and CNQX and AP5 are inotropic glutamate receptor antagonists. Both control and test solutions were applied through a perfusion pipette using a gravity-driven device controlled by a microsolenoid valve.

To record changes in the holding current the cerebellar granule neurons were held at a membrane potential of $-60 \mathrm{mV}$ and the glutamate-induced current was recorded. To avoid any misinterpretation due to variations in the holding current not caused by the external application of glutamate, we compared the change of the slope of the voltage-ramp induced-currents in response to the application of L-glutamate.

\section{Data analysis}

Dose-response data were fitted to the Michaelis-Menten equation, $I=I_{\max }[\mathrm{Glu}] /$ $\left([\mathrm{Glu}]+K_{\mathrm{m}}\right)$, where $I$ is the glutamate-elicited current, $I_{\max }$ is the maximal current activated by glutamate, [Glu] is the substrate, and $K_{\mathrm{m}}$ is the concentration of substrate that generates a half-maximal current increase. All values are reported as means $\pm \mathrm{SEM}$ and data were analyzed statistically by the twotailed Student $t$-test. The data were analyzed using a combination of Pulse-Fit (HEKA), and SigmaPlot (Jandel Scientific, Chicago, IL, USA) softwares.

\section{Results}

\section{L-Glutamate-elicited currents in cerebellar granule neurons}

To determine whether granule neurons express functional glutamate transporters, whole-cell recordings were obtained from cells that had been maintained in culture for at least 5 days. External application of $1 \mathrm{mM}$ glutamate produced an inward shift of the holding current at $-60 \mathrm{mV}$ (Figure 1A). During periods as long as $50 \mathrm{~s}$ the presence of glutamate produced little or no macroscopic desensitization or inactivation under the recording condi-

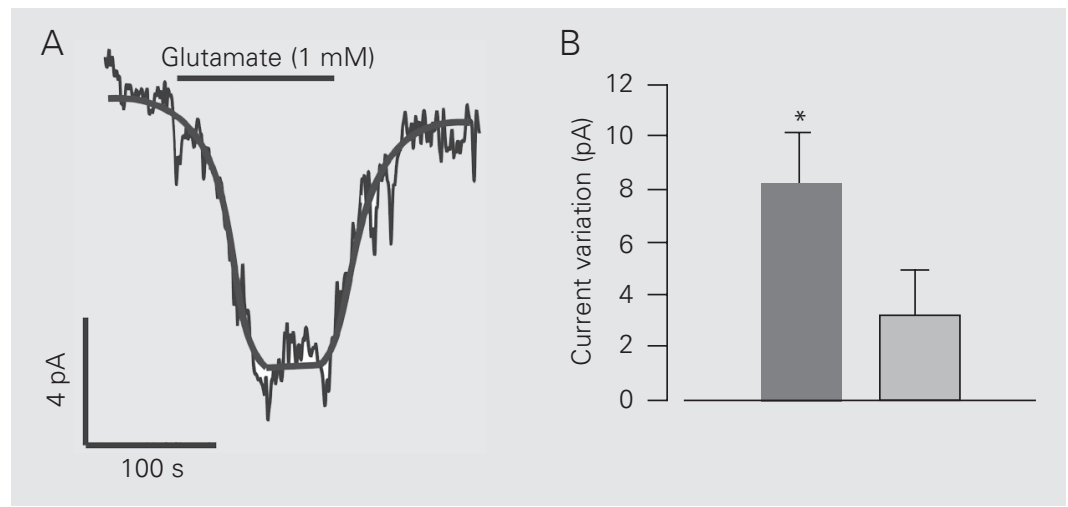

Figure 1. L-Glutamate-elicited current in granule neurons. $A$, Whole-cell current evoked by $1 \mathrm{mM} \mathrm{L}$-glutamate in neurons held at $-60 \mathrm{mV}$. The record represents the mean current from eight cells. The continuous line was drawn by eye. $B$, Bar graph showing the mean steadystate amplitude of whole-cell currents evoked in eight cells by $1 \mathrm{mM}$ L-glutamate (dark gray column) and after washing out (light gray column). Error bars indicate SEM. ${ }^{*} \mathrm{P}<0.01$ compared to washout cells (two-tailed Student $t$-test). 
tions employed (Figure 1A). This allowed us to study the voltage dependence of the glutamate-induced current by applying voltage ramps during the steady-state phase current responses. Figure 1B presents the composite data showing a mean current value of $8.14 \pm$ $1.9 \mathrm{pA}(\mathrm{N}=8, \mathrm{P}<0.01)$. At this point we concluded that cerebellar granule neurons respond to the application of glutamate by generating an inward current that could not be attributed to the simple activation of glutamate
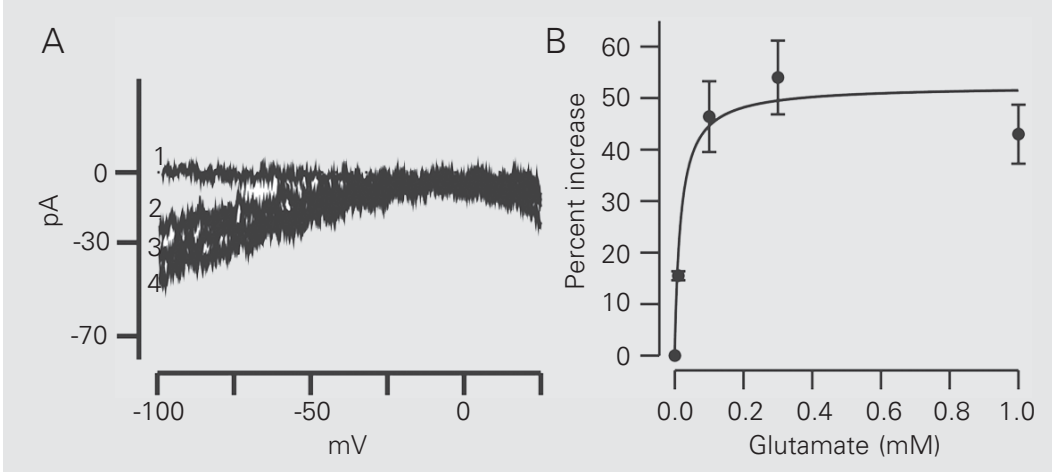

Figure 2. Dose- and voltage-dependent currents due to the perfusion of granule neurons with L-glutamate. A, I-V relationships for L-glutamate-sensitive currents measured during 100 -ms voltage ramps from -100 to $+25 \mathrm{mV}$. L-Glutamate concentration was 1) $10 \mu \mathrm{M}, 2$ ) $100 \mu \mathrm{M}$, 3) $300 \mu \mathrm{M}$, and 4) $1000 \mu \mathrm{M}$. B, Average dose-response curve for the L-glutamatesensitive current in five cells. The smooth curve is the best-fit: maximum percent increase $=51.2 \pm 4.4 \%$ and $K_{\mathrm{m}}=18.3 \pm 0.9 \mu \mathrm{M}(\mathrm{N}=5)$.

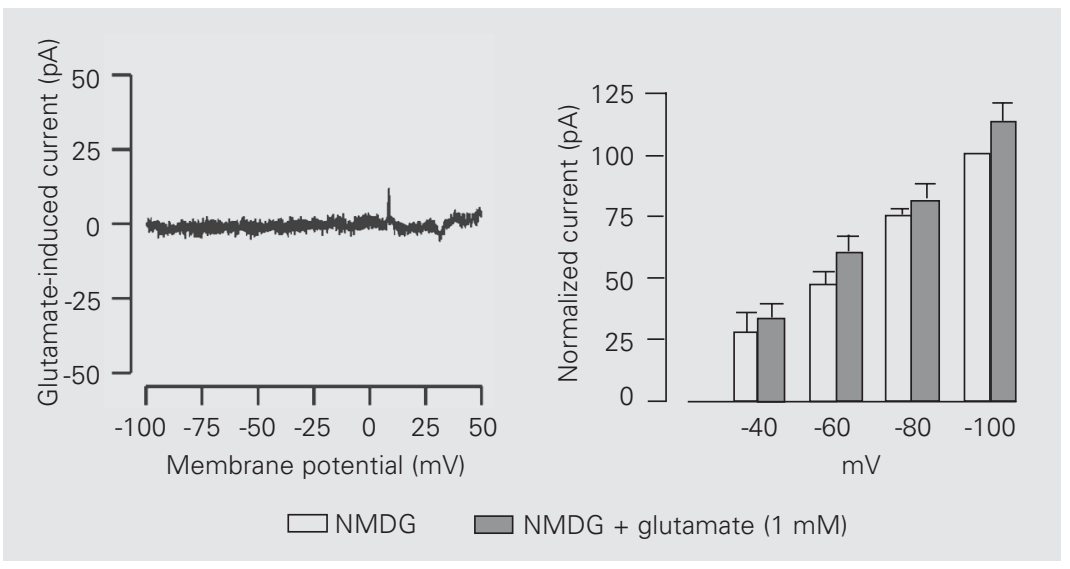

Figure 3. Dependence of L-glutamate-evoked currents on external $\mathrm{Na}^{+}$in granule neurons. A, Representative I-V relationships obtained when N-methyl-D-glucamine (NMDG) was substituted for $\mathrm{Na}^{+}$in a granule neuron. The result is the difference in current obtained by subtracting the current during perfusion of L-glutamate $(1 \mathrm{mM})$ from the current in the absence of L-glutamate. Five different cells were used and all presented the same result. $B$, Bar graph showing the composite data for five cells. There was no statistically significant difference among the potentials examined. Data are reported as means \pm SEM. receptors, since we were using a cocktail of specific blockers. We then raised the possibility that the observed inward current could be due to the presence of a glutamate transport mechanism. We therefore decided to look first at the electrophysiological features of that glutamate-induced current. By using a voltageramp protocol as a way to obtain fast responses to glutamate application, we designed an experiment to establish if there was concentration dependence for the observed current.

As shown in Figure 2A, as we increased glutamate concentration from 10 to 1000 $\mu \mathrm{M}$ an increasing inward current was observed at membrane potentials negative to $-25 \mathrm{mV}$. The I-V relationship is similar to that reported previously by others $(23,24)$. Figure $2 \mathrm{~B}$ shows the dose-response curve for the composite data. The current size was taken at $-100 \mathrm{mV}$ and it could be well fitted by a Michaelis-Menten-type dependence on [Glu $]_{o}$ with an estimated $K_{\mathrm{m}}$ of $18.3 \pm 0.9 \mu \mathrm{M}$ and a maximum increase of $51.2 \pm 4.4 \%$ $(\mathrm{N}=5)$. The $K_{\mathrm{m}}$ value was close to those found previously for EAAT2/GLT1 in different expression systems $(25,26)$.

\section{Extracellular $\mathrm{Na}^{+}$removal abolishes the glutamate-elicited current}

The glutamate-elicited inward current was completely abolished when extracellular $\mathrm{Na}^{+}$was replaced by $\mathrm{N}$-methyl-D-glucamine (Figure 3A, $\mathrm{N}=5$ ), consistent with the wellestablished idea that glutamate transport requires $\mathrm{Na}^{+}$. Figure 3B shows the pooled data obtained at different voltages, showing that there was no difference between groups. This evidence leads us to suggest that cerebellar granule neurons express a $\mathrm{Na}^{+}$-dependent glutamate transporter.

\section{Dihydrokainate inhibited the glutamate- induced current}

We next asked which subtype was being expressed. As indicated by McIllvain et al. 
(21) using immunoreactivity analysis, the cerebellar granule neurons expressed the EAAT2 and EAAT3 isoforms. Following this rationale we decided to determine if dihydrokainate, a glutamate analog that binds specifically to EAAT2/GLT1 $(25,26)$, would have an effect. In most of the cells studied, like the cell in Figure 4A, the glutamateinduced current was partially blocked (tracing No. 2). On average, the response to $1 \mathrm{mM}$ glutamate was reduced by $25.05 \pm 8.4 \%$ by $500 \mu \mathrm{M}$ dihydrokainate (Figure $4 \mathrm{C}, \mathrm{N}=5$ ). Figure 4B shows the response of a typical cell when dihydrokainate concentration was doubled and L-glutamate concentration was decreased by half of that previously used. As one would expect for a competitive inhibitor, dihydrokainate completely blocked the response to L-glutamate $(\mathrm{N}=5)$.

\section{Discussion}

The data presented here characterize the voltage and $\mathrm{Na}^{+}$dependence, and the pharmacology of the glutamate-induced current in cerebellar granule neurons. Immunoreactivity to the GLT1, GLAST, EAAT1 and EAAT4 subtypes of glutamate transporters was described in the developing rat cerebellar cortex $(8,27)$ but very few electrophysiological data characterizing the presence of an electrogenic glutamate transporter in cerebellar granule neurons are available.

Our results provide evidence that granule neurons exhibit an inward current activated by glutamate (Figure 1A). The macroscopic currents were measured under conditions of glutamate receptor blockade. The current amplitude varied from 5 to $20 \mathrm{pA}$ when measured under steady-state conditions with the membrane potential held at $-60 \mathrm{mV}$ (Figure 1B). The current activated by glutamate was voltage dependent, showing a strong inward rectification (Figure 2A). In a certain number of cells we noticed an outward component (Figure 4A) that could be the result of $\mathrm{Cl}^{-}$ion influx into the cell due to the activa- tion of anion conductance in the carrier structure. Another possibility is that during glutamate transport the accumulation of $\mathrm{Na}^{+}$ions into the cell caused the reversed operation of the transporter (28).

The transport of L-glutamate is driven in part by the thermodynamically coupled cotransport of $\mathrm{Na}^{+}$ions down their electrochemical gradient (29). Thus, removal of $\mathrm{Na}^{+}$from the extracellular medium eliminates glutamate transport. We did replace extracellular $\mathrm{Na}^{+}$with $\mathrm{N}$-methyl-D-glucamine and we eliminated both the inward and outward currents elicited by L-glutamate (Figure $3 \mathrm{~A}$ ), suggesting that the current is probably generated by a $\mathrm{Na}^{+}$-dependent mechanism. Furthermore, replacing $\mathrm{Na}^{+}$with $\mathrm{Li}^{+}$ eliminated the glutamate-induced current as well, showing that the current was not due to some residual unblocked inotropic receptor (data not shown).

The calculated $K_{\mathrm{m}}$ was comparable to the values obtained with other transporter subtypes in different preparations $(25,26,30)$, suggesting that the expression of a high affinity glutamate transporter in cerebellar granule neurons may allow them to act efficiently during the glutamate clearance.

We observed a partial block of the current activated by glutamate in cerebellar granule neurons by dihydrokainate, which is a transporter inhibitor (Figure 4A,C). Since dihydrokainate has been reported to inhibit glutamate transport competitively, we used $1 \mathrm{mM}$ dihydrokainate and observed a total block of the current activated by $500 \mu \mathrm{M}$ glutamate (Figure 4B,D). The pharmacological signature we found for glutamate transport in cerebellar granule neurons matches that reported for the cloned EAAT2/GLT1 transporters (25). Based on the above observations, we suggest that cerebellar granule neurons express predominantly the EAAT2/ GLT1 glutamate transporter subtype.

Several authors agree about the localization of glutamate transporters. EAAC1 and EAAT4 are selectively localized in neurons 
Figure 4. Pharmacology of L-glutamate-evoked current in granule neurons. A, I-V relationships obtained under the following conditions: 1) $1 \mathrm{mM}$ L-glutamate, 2) $1 \mathrm{mM}$ L-glutamate in the presence of $500 \mu \mathrm{M}$ dihydrokainate (DHK), and 3) DHK washout and maintenance of 1 mM L-glutamate. All three waveforms were digitally subtracted from the control. $B$, The same experiment as $A$ but with the addition of $1 \mathrm{mM}$ DHK in the presence of $500 \mu \mathrm{M}$ L-glutamate. 1) Waveform obtained in response to L-glutamate; 2) 500 $\mu \mathrm{M}$ L-glutamate + $1 \mathrm{mM}$ DHK, and 3) after DHK washout. C, Composite data where $a$ is the control, $b$ after $1 \mathrm{mM}$ L-glutamate, c $1 \mathrm{mM}$ L-glutamate +500 $\mu \mathrm{M}$ DHK, and $d$ DHK washout. Data are the average of five cells. Error bars indicate the SEM. $D$, Same as in $C$ but using $1 \mathrm{mM}$ DHK and $500 \mu \mathrm{M}$ L-glutamate. Data are the average for five different cells. Error bars indicate the SEM. The asterisks denote $P<0.05$ compared to control (paired $t$-test).

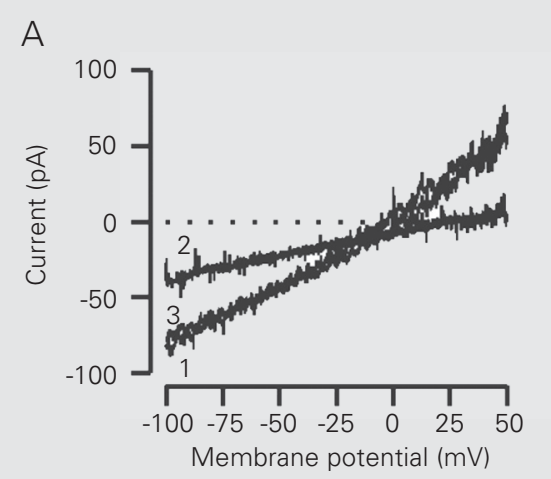

C

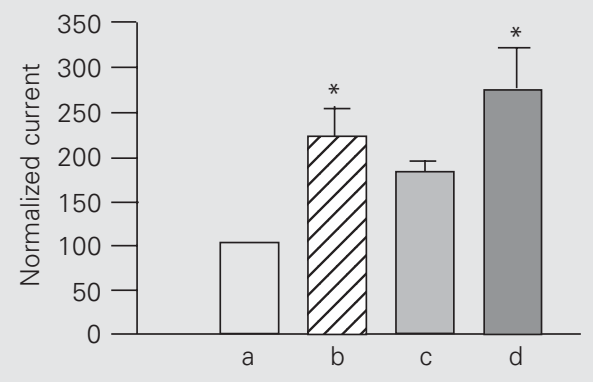

(9), whereas GLT1 and GLAST are astroglial transporters (10). However, controversies are emerging about the exclusively glial localization of the GLT1 subtype. Mice lacking the GLT1 transporter revealed a drastic decrease in synaptosomal transport, suggesting the possibility of neuronal expression of GLT1 (6). Although glial contamination cannot be ruled out, there are some reports describing detectable levels of GLT1 expression in glial-poor cultures of cortical neurons and a significant contribution of dihydrokainate-sensitive transport to neuronal glutamate uptake (31).

The present findings are important as the first electrophysiological demonstration that cerebellum neurons express the functional EAAT2/GLT1 glutamate transporter. However, we cannot rule out the possibility of a

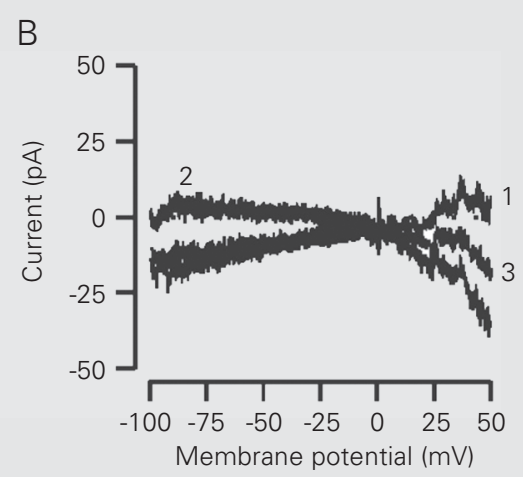

D

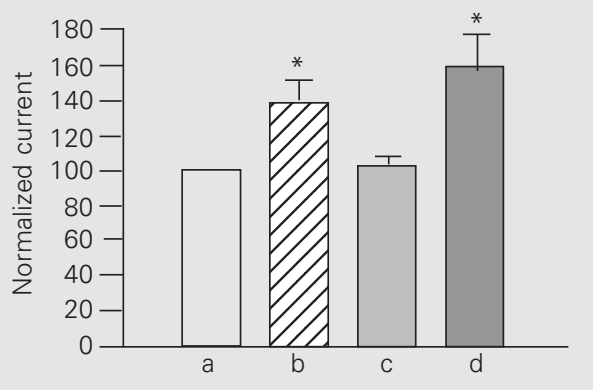

novel neuronal glutamate transporter that shows sensitivity to dihydrokainate. We still do not know exactly how glutamate is returned to the presynaptic terminal after synaptic release. Compelling evidence exists for a glutamine/glutamate cycle with the concomitant participation of astrocytes that take up the glutamate released and convert it to glutamine, which can then be transferred to neurons to be used. An alternate possibility is that glutamate may be transported by the presynaptic terminal itself and in this way help to reduce the possibly toxic glutamate concentration. Clearly, further studies are needed to elucidate the molecular basis of the transport activity described in this study, which may play an important role in the normal and abnormal physiology of the cerebellum. 


\section{References}

1. Diamond JS \& Jahr CE (2000). Synaptically released glutamate does not overwhelm transporters on hippocampal astrocytes during highfrequency stimulation. Journal of Neurophysiology, 83: 2835-2843.

2. Tong G \& Jahr CE (1994). Block of glutamate transporters potentiates postsynaptic excitation. Neuron, 13: 1195-1203.

3. Voght KE \& Nicoll RA (1999). Glutamate and gamma-aminobutyric acid mediate a heterosynaptic depression at mossy fiber synapses in the hippocampus. Proceedings of the National Academy of Sciences, USA, 96: 1118-1122.

4. Mitchell SJ \& Silver RA (2000). Glutamate spillover suppresses inhibition by activating presynaptic mGluRs. Nature, 404: 498-502.

5. Lin CL, Bristol LA, Jin L, Dykes-Hoberg M, Crawford T, Clawson L \& Rothstein JD (1998). Aberrant RNA processing in a neurodegenerative disease: the cause for absent EAAT2, a glutamate transporter, in amyotrophic lateral sclerosis. Neuron, 20: 589-602.

6. Tanaka K, Watase K, Manabe T et al. (1997). Epilepsy and exacerbation of brain injury in mice lacking the glutamate transporter GLT-1. Science, 276: 1699-1702.

7. Rothstein JD, Dykes-Hoberg M, Pardo CA et al. (1996). Knockout of glutamate transporters reveals a major role for astroglial transport in excitotoxicity and clearance of glutamate. Neuron, 16: 675-686.

8. Danbolt NC (2001). Glutamate uptake. Progress in Neurobiology, 65: 1-105.

9. Rothstein JD, Martin L, Levey Al, Dykes-Hoberg M, Jin L, Wu D, Nash N \& Kunkl R (1994). Localization of neuronal and glial glutamate transporters. Neuron, 13: 713-725.

10. Lehre KP, Levy LM, Ottersen OP, Storm-Mathisen J \& Danbolt NC (1995). Differential expression of two glial glutamate transporters in the rat brain: quantitative and immunocytochemical observations. Journal of Neuroscience, 15: 1835-1853.

11. Peghini P, Janzen J \& Stoffel W (1997). Glutamate transporter EAAC-1-deficient mice develop dicarboxylic aminoaciduria and behavioral abnormalities but no neurodegeneration. EMBO Journal, 16: 3822-3832.

12. Jakab RL \& Hamori J (1988). Quantitative morphology and synaptology of cerebellar glomeruli in the rat. Anatomy and Embryology, 179: 81-88.

13. Wall MJ \& Usowicz MM (1998). Development of the quantal properties of evoked and spontaneous synaptic currents at a brain synapse. Nature Neuroscience, 1: 675-682.

14. Rossi DJ \& Hamann M (1998). Spillover-mediated transmission at inhibitory synapses promoted by high affinity alpha6 subunit GABA(A) receptors and glomerular geometry. Neuron, 20: 783-795.

15. Leão RM, Mellor JR \& Randall AD (2000). Tonic benzodiazepinesensitive GABAergic inhibition in cultured rodent cerebellar granule cells. Neuropharmacology, 39: 990-1003.

16. Sarantis M, Ballerini L, Miller B, Silver RA, Edwards M \& Attwell D (1993). Glutamate uptake from the synaptic cleft does not shape the decay of the non-NMDA component of the synaptic current.
Neuron, 11: 541-549.

17. Takahashi M, Sarantis M \& Attwell D (1998). Glutamate uptake in Purkinje cells in rat cerebellar slices. Methods in Enzymology, 296: 608-617.

18. Otis TS, Wu Y-C \& Trussell LO (1996). Delayed clearance of transmitter and the role of glutamate transporters at synapses with multiple release sites. Journal of Neuroscience, 16: 1634-1644.

19. Overstreet LS, Kinney GA, Liu YB, Billups D \& Slater NT (1999). Glutamate transporters contribute to the time course of synaptic transmission in cerebellar granule cells. Journal of Neuroscience, 19: 9663-9673.

20. Mennerick S \& Zorumski CF (1994). Glial contributions to excitatory neurotransmission in cultured hippocampal cells. Nature, 368: 5962.

21. Mclllvain HB, Lou Z \& Dunlop J (1999). Expression of excitatory amino-acid transporters in rat cerebellar granule neuron cultures. Society for Neuroscience Abstracts, 25: 171 (Abstract 15).

22. Hamill OP, Marty A, Neher E, Sakmann B \& Sigworth FJ (1981). Improved patch-clamp techniques for high-resolution current recording from cells and cell-free membrane patches. Pflügers Archiv. European Journal of Physiology, 391: 85-100.

23. Wadiche JI, Arriza JL, Amara SG \& Kavanaugh MP (1995). Kinetics of a human glutamate transporter. Neuron, 14: 1019-1027.

24. Eliasof S, Arriza JL, Leighton BH, Kavanaugh MP \& Amara SG (1998). Excitatory amino acid transporters of the salamander retina: identification, localization, and function. Journal of Neuroscience, 18: 698-712.

25. Arriza JL, Fairman WA, Wadiche JI, Murdoch GH, Kavanaugh MP \& Amara SG (1994). Functional comparisons of three glutamate transporter subtypes cloned from human motor cortex. Journal of Neuroscience, 14: 5559-5569.

26. Pines G, Danbolt NC, Bjoras $M$, Zhang $Y$, Bendahan A, Eide L, Koepsell H, Seeberg E, Storm-Mathisen J \& Kanner BI (1992). Cloning and expression of a rat brain L-glutamate transporter. $\mathrm{Na}$ ture, 360: 464-467.

27. Furuta $A$, Martin LJ, Lin $C L$, Dykes-Hoberg $M$ \& Rothstein JD (1997). Cellular and synaptic localization of the neuronal glutamate transporters excitatory amino acid transporter 3 and 4 . Neuroscience, 81: 1031-1042.

28. Billups B \& Attwell D (1996). Modulation of non-vesicular glutamate release by $\mathrm{pH}$. Nature, 379: 171-174.

29. Zerangue N \& Kavanaugh MP (1996). Flux coupling in a neuronal glutamate transporter. Nature, 383: 634-637.

30. Eliasof S, Arriza JL, Leighton BH, Amara SG \& Kavanaugh MP (1998). Localization and function of five glutamate transporters cloned from the salamander retina. Vision Research, 38: 1443-1454.

31. Wang GJ, Chung HJ, Schnuer J, Pratt K, Zable AC, Kavanaugh MP \& Rosenberg PA (1998). High affinity glutamate transport in rat cortical neurons in culture. Molecular Pharmacology, 53: 88-96. 